\title{
Nasal response of rhinitic and non-rhinitic subjects to histamine and methacholine: a comparative study
}

\author{
O J CORRADO, C A L GOULD, J Y KASSAB, R J DAVIES
}

\begin{abstract}
From the Chest Department, St Bartholomew's Hospital, London, and the Statistics Unit, University College of North Wales, Bangor
\end{abstract}

ABSTRACT The nasal responses to provocation with histamine and methacholine were compared in 20 subjects with and 20 without rhinitis. Two variables were measured: nasal airways resistance and the development of rhinorrhoea. Histamine had a greater effect than methacholine in increasing nasal airways resistance while the converse was true for rhinorrhoea. Rhinitic subjects had a significantly greater response to histamine induced changes in nasal airways resistance $(p<0.05)$, rhinorrhoea $(p<0.05)$ and methacholine induced rhinorrhoea $(p<0.01)$ than those without rhinitis. No significant differences were found between the two groups in methacholine induced changes in nasal airways resistance. The findings show that, like the lower airways of patients with asthma, the nasal mucosa of rhinitic subjects shows a greater responsiveness to non-specific agonists than that of non-rhinitic subjects.

It is well recognised that the lower airways of subjects with asthma show a greater responsiveness to various non-specific stimuli, including the pharmacological agents histamine and methacholine, than those of subjects without asthma. ${ }^{1-4}$ The enormous number of reports on various aspects of bronchial reactivity provides a striking contrast to the limited attention devoted to the study of the upper respiratory tract. The results of studies of the upper respiratory tract have generally shown poor agreement and it remains unclear whether the nasal mucosa of patients with rhinitis is more responsive to pharmacological agonists than that of non-rhinitic subjects. ${ }^{5-12}$

The nasal response to provocation can be measured in several ways. ${ }^{13} \mathrm{~A}$ nasal challenge may cause pruritus and sneezing from stimulation of nerve endings, nasal obstruction from vascular dilatation and oedema, and rhinorrhoea from stimulation of mucosal glands. ${ }^{1314}$ The purpose of this study was, firstly, to re-examine whether an increased level of non-specific responsiveness of the nasal mucosa is a feature of rhinitis and, secondly, to determine whether any differences exist in the pattern of response to provocation with histamine and metha-

Address for reprint requests: Dr R J Davies, Chest Department, St Bartholomew's Hospital, London EC1A 7BE.

Accepted 15 May 1986 choline by measuring change in both nasal airways resistance and rhinorrhoea in the same subjects.

\section{Methods}

\section{SUBJECTS}

We studied 20 patients with perennial allergic rhinitis who had symptoms and who were selected at random from those attending outpatient clinics. The 13 female and seven male subjects were aged 17-40 (mean 26) years. They had suffered from perennial rhinitis ${ }^{7}$ for from one to 25 years (mean nine years), experiencing symptoms for one to 16 hours a day (mean seven hours). All patients had a positive skinprick test response and a positive response to a nasal provocation test with either Dermatophagoides pteronyssinus (18 subjects) or cat fur extract (two subjects). Seventeen patients were having no current medication for their rhinitis, one patient had regularly been using the $\mathrm{H}_{1}$ antihistamine chlorpheniramine maleate (slow release) $10 \mathrm{mg}$ at night, and two were using intranasal beclomethasone dipropionate. These patients discontinued all treatment three days before the study.

We also studied a control group of 20 healthy volunteers ( 11 female, age range 19-35, mean 26 years) with no history of rhinitis or other nasal disease, asthma, or eczema, and with negative skinprick test responses to four common allergens (Dermatophagoides pteronyssinus, house dust, grass pollen, and Aspergillus fumigatus). Control subjects were 
matched with the rhinitic subjects for age and sex so far as possible. None of the 40 subjects had evidence of either nasal polyposis or deformity on anterior rhinoscopy. Solutions were made of methacholine bromide (Sigma Chemical Co Ltd, Poole, Dorset) in distilled water ${ }^{7}$ at concentrations of $15,30,60,120$, and $240 \mathrm{mg} / \mathrm{ml}$ and histamine acid phosphate (BDH Chemicals Ltd, Dagenham, Essex) in isotonic saline $(0.9 \% \mathrm{w} / \mathrm{v})$ at concentrations of $1,2 \cdot 5,5,10$, and $25 \mathrm{mg} / \mathrm{ml}$. Fresh solutions of both agonists were prepared at two week intervals. Buffered phenol saline $(0.5 \% \mathrm{w} / \mathrm{v}$ saline, $0.275 \% \mathrm{w} / \mathrm{v}$ sodium bicarbonate, $0.4 \% \mathrm{w} / \mathrm{v}$ phenol), $\mathrm{pH} 7 \cdot 0$, was used as the control solution.

The control solution and each concentration of agonist were nebulised in a volume of $100 \mu$, at an air flow rate of $71 \mathrm{~min}^{-1}$, from a cuvette using a modified air spray (Humbrol, Hull). The administration of each solution took about three seconds. To reduce exposure of the lower airways to the agonist solutions, subjects were instructed to hold their breath in inspiration while the solutions were being nebulised and to exhale through the mouth immediately after delivery.

The response to nasal provocation was measured in terms of nasal airways resistance and nasal secretions. Nasal airways resistance was measured in each nostril separately, by a technique of passive anterior rhinomanometry, with the nasal airways resistance tester (PK Morgan Ltd, Chatham, Kent) originally described by Britton and coworkers. ${ }^{15}$ Each measurement of nasal airways resistance was taken as the mean of five consecutive readings recorded within 30 seconds. Nasal secrections were collected by asking subjects to incline their head slightly forward over a graduated test tube equipped with a glass funnel held below the challenged nostril.

\section{PROTOCOL}

Nasal provocation tests with histamine and methacholine were performed one week apart, in a random order, on each subject. The study had an open design. Nasal airways resistance was measured in each nostril before provocation. Buffered phenol saline was nebulised into the nostril with the lower initial level of nasal airways resistance and the resistance was measured again two and five minutes later. Increasing concentrations of the agonist were then administered to the same nostril and measurements of nasal airways resistance made two and five minutes after each administration. Nasal secretions were collected from the time of administration of each dose of agonist and continued between measurements of nasal airways resistance. The total volume of nasal secretions collected during each provocation test was recorded.

\section{ANALYSIS OF RESULTS}

The sample size $(\mathrm{n})$ required to detect a significant difference in change in nasal airways resistance of $0.75 \mathrm{kPal}^{-1} \mathrm{~s}$ between the agonist and the controlo solution with a power of $80 \%$ was 20 subjects in each $\frac{\widetilde{\nabla}}{2}$ group. These calculations were based on a one tail test, at a significance level of $5 \%$, with the differences in nasal airways resistance normally distributed with $\vec{\circ}$ a variance equal to $1 \cdot 85$.

Change in nasal airways resistance was evaluated in $\vec{\omega}$ the challenge nostril only The maximum change in resistance recorded at two or five minutes after each $x$

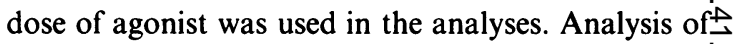
nasal airways resistance at each dose, plots of group means against standard deviation (SD) and variance, $\vec{\circ}$ and probability plots showed that the SD varied $\mathcal{E}^{\infty}$ directly with the mean, that the variances were het-o erogenous, and that the data were heavily skewed to the right, indicating non-normality of distribution. $z$ More formal assessments using KolmogorovSmirnov and Cochran's tests confirmed these findings and suggested that logarithmic transformation of the data would be appropriate, as concluded by Brittonet al. ${ }^{15}$

Comparisons of nasal airways resistance values ${ }^{\infty}$ before provocation, and change in resistance after the control solution in the two groups of subjects weres made on log transformed values with paired and unpaired Student's $t$ tests as appropriate. Changes in resistance after administration of each agonist were $\frac{0}{\Omega}$ related and compared with those produced by the instillation of the control solution, a two factor ana윽 lysis of variance (ANOVA) being used for repeated measures. Multiple comparisons were made with the Newman-Keuls test. The analyses were performed by means of the statistical package for the social scienceso (SPSS) ${ }^{16}$ on the computer at the University College of North Wales, Bangor. The number of subjects ins each group producing nasal secretions in response to provocation with each agonist were compared with the help of $2 \times 2$ contingency tables and Fisher's exact test.

\section{Results}

The nasal provocation tests with histamine and metho acholine in the doses used in this study were welD tolerated, although the two highest doses of meth acholine $(22.5$ and $46.5 \mathrm{mg})$ produced transient faciab flushing in almost all subjects, as noted previously.

NASAL AIRWAYS RESISTANCE

Measurements of nasal airways resistance before provocation on the two test days ranged from 0.04 to. 0.54 (geometric mean (GM) $0 \cdot 12) \mathrm{kPa} \mathrm{l}^{-1} \mathrm{~s}$ and from 0.02 to $0.49(\mathrm{GM} 0.09) \mathrm{kPa}^{-1} \mathrm{~s}$ in rhinitic subjects 


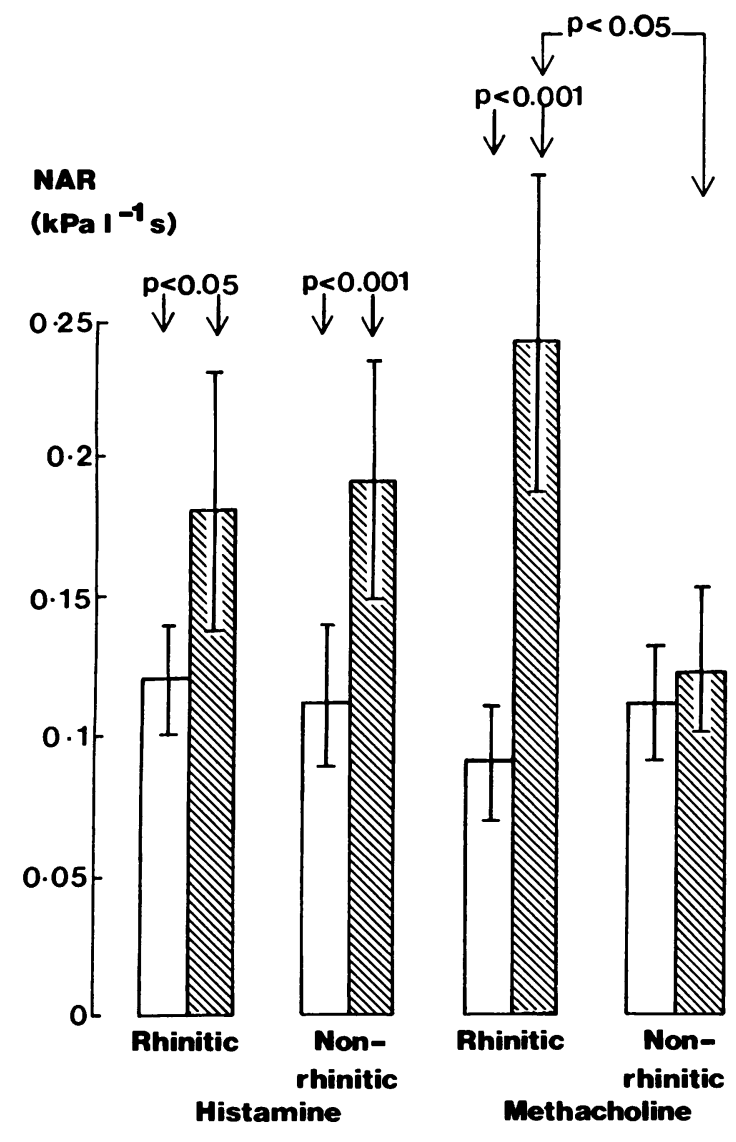

Fig 1 Nasal airways resistance (NAR) in the challenge nostril of subjects with and without rhinitis before provocation $\square$ and after buffered phenol saline $\mathbb{Q}$.

and from 0.01 to $0.92(\mathrm{GM} 0 \cdot 11) \mathrm{kPa}^{-1} \mathrm{~s}$ and from 0.01 to $0.48(\mathrm{GM} 0.11) \mathrm{kPa}^{-1} \mathrm{~s}$ in non-rhinitic subjects. There were no significant differences between these measurements (fig 1).

The changes in nasal airways resistance after buffered phenol saline were not consistent. On the histamine test day there was a significant increase in resistance in both rhinitic and control subjects, while on the methacholine test day only those with rhinitis showed a significant increase, which was greater than that occurring in those without rhinitis $(t$ test; $p<$ 0.05-fig 1).

Histamine produced a dose related increase in nasal airways resistance in subjects both with and without rhinitis (analysis of variance; $p<0.001$ ). The response of rhinitic subjects was significantly greater than that of non-rhinitic subjects ( $p<0.05-$ fig 2 ). The difference in nasal airways resistance between the two groups varied significantly ( $p<0.01$ ) with the dose of histamine, producing dose-response curves of different shapes for the two groups, (fig 2). In rhinitic subjects increasing doses of histamine produced significantly greater increases in nasal airways resistance, while in the non-rhinitic subjects only the highest dose of histamine used $(4.35 \mathrm{mg})$ produced a significantly greater nasal airways resistance than buffered phenol saline.

Methacholine produced a greater increase in nasal airways resistance than did buffered phenol saline in both groups of subjects $(p<0.01)$, but this was less than the change produced by histamine, and not dose related (fig 2). There were no significant differences between subjects with and without rhinitis $(p<0 \cdot 10)$.

\section{NASAL SECRETIONS}

Rhinorrhoea occurred in 12 subjects with and three without rhinitis in response to methacholine and in five subjects with but none without rhinitis in response to histamine, the difference between methacholine and histamine being significant for all subjects combined $(p<0.02)$. Four of the five subjects who produced secretions in response to histamine also produced secretions in response to methacholine. Rhinitic subjects had a significantly greater response to methacholine $(p<0.01)$ and histamine $(p<0.05)$

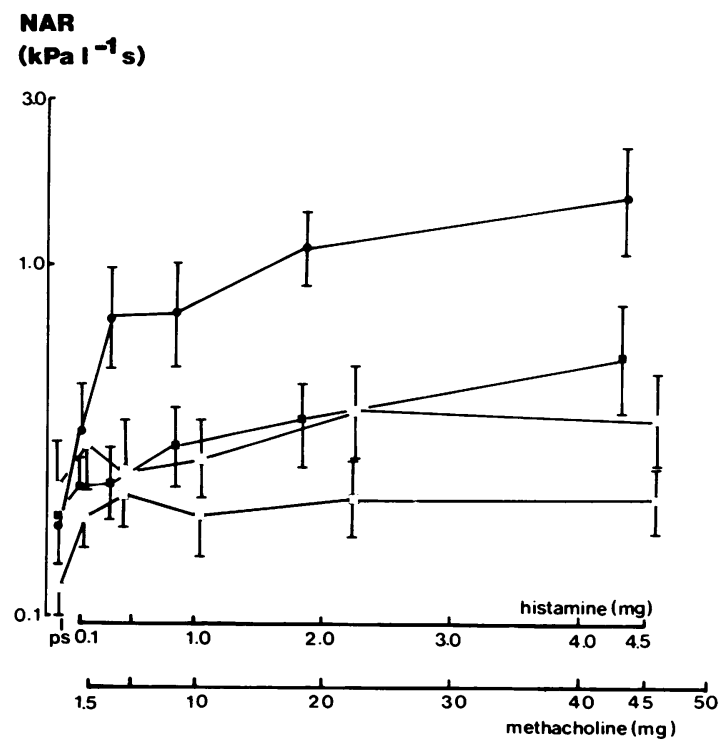

Fig 2 Effect of administration of buffered phenol saline $(P / S)$ and increasing doses ( $\mathrm{mg}$ ) of histamine (closed symbols) and methacholine (open symbols) on the nasal airways resistance $(N A R)$ of rhinitic $(O, O)$ and non-rhinitic $(\square, \square)$ subjects. The geometric means and standard errors are shown on a logarithmic scale. 


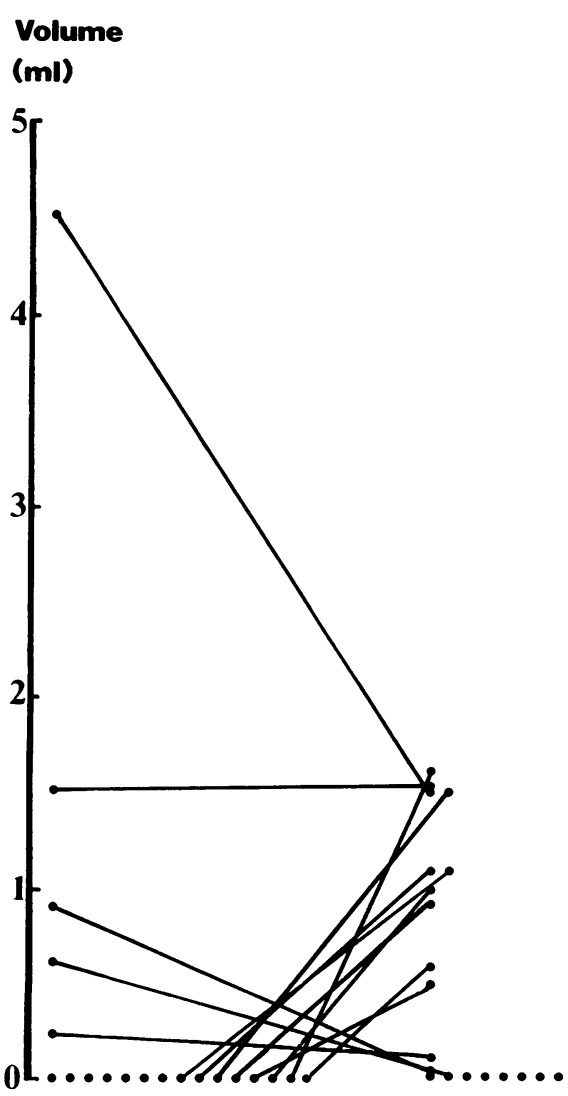

Histamine Methacholine

Rhinitic Subjects

Fig 3 Amount of nasal secretions produced by subjects with rhinitis in response to provocation with histamine and methacholine. The solid lines join each subject's response to histamine and methacholine.

than non-rhinitic subjects. The difference in the proportions of rhinitic subjects who produced secretions in response to methacholine and in response to histamine was of borderline significance $(p=0.054)$ and there was no significant difference between the responses of non-rhinitic subjects to the two agonists $(p>0.20)$ (fig 3 ). We could not compare the volumes of secretions produced by the two groups of subjects, since only three non-rhinitic subjects produced secretions.

\section{Discussion}

This is the first report in which the nasal responses to histamine and methacholine of subjects with and without rhinitis have been compared by measuring $\Rightarrow$ change in nasal airways resistance and rhinorrhoea.? In this study the nasal response to provocation was? greater in those with than those without rhinitis.

There are important differences in the pattern of response to these agonists that may partially explain the confusing and contradictory results of previous studies. We found that histamine had a greater effect $\overrightarrow{-}$ in inducing nasal obstruction than rhinorrhoea and:that the opposite was true for methacholine. The $\vec{\omega}$ increased nasal reactivity of rhinitic subjects to histamine could be detected by measuring changes in nasal $\vec{x}$ airways resistance and rhinorrhoea. Differencesi between the responses of subjects with and without rhinitis to methacholine, however, could be detected $-\overrightarrow{+}$ only by recording the amount of secretions produced. क्

The importance of measuring more than one vari-o able in response to nasal provocation for the evaluation of nasal reactivity has been emphasised by others. ${ }^{1317}$ This may, however, present problems. WeO encountered difficulties in combining measurement of $\frac{\mathbb{D}}{3}$ nasal airways resistance with the volume of nasalo secretions. The method of rhinomanometry used in $\stackrel{\mathbb{}}{ }$ this study ${ }^{15}$ has a tendency to clear secretions and this $\overrightarrow{0}$ may have reduced the amount of secretions collectedo from the nose. The interpretation of the effect of ago-ס nist provocation on nasal airways resistance should ideally be related to changes in resistance produced by the administration of a control solution. ${ }^{13}$ We usedo buffered phenol saline and found, like other workers, $\stackrel{\circ}{\Phi}$ that this caused significant changes in nasal airways resistance, ${ }^{18}$ though these were not found consis-응 tently. As phenol is a potential nasal irritant, a solu- $\frac{3}{5}$ tion such as isotonic saline would have been a better control. It might have been better to determine the nasal response to repeated administrations of the con- $-\overrightarrow{0}$ trol solution alone on a separate test day for comparison with the responses to the two agonists. Hista- $-x$ mine and cholinergic agonists have been used to 3 . assess the reactivity of the lower respiratory tract for almost 40 years. The lower airways of subjects with 3 asthma have a greater response to these agonists than healthy subjects with no history of pulmonary or? allergic disease. ${ }^{1-4}$ Rhinitic subjects who have no his $\frac{D}{0}$ tory of asthma have an increased bronchial reactivity to these agents, although less than that of asthmatic ${ }_{\sigma}$ subjects. ${ }^{1920}$ Several studies have failed to show similar differences in the cutaneous response of atopic and non-atopic subjects to histamine and meth- $\omega$ acholine. ${ }^{520-22}$ Little attention has been devoted to the study of the reactivity of the upper respiratory tract to non-specific stimuli. Many individuals with rhinitis report a heightened nasal response to irritantssuch as cigarette smoke and strong perfumes. There ${ }_{-}^{-}$ is, however, conflicting evidence on whether clear differences between the nasal reactivity of rhinitic and $\frac{\text { }}{\overparen{ }}$ 
non-rhinitic subjects can be detected. Girard and coworkers found that rhinitic subjects had a greater response to both histamine and bradykinin than control subject's ${ }^{6}$ - a finding that has been confirmed by some workers ${ }^{71112}$ but not others. ${ }^{589}$ Histamine is thought to exert an effect on the nasal mucosa in two ways ${ }^{14}$ - by a direct effect on receptors, leading to vasodilation and oedema, and indirectly via the trigeminal and vidian neural reflex arc, resulting principally in glandular stimulation with the production of secretion. Cholinergic stimulation of the nasal mucosa is thought to cause glandular secretion mainly. ${ }^{14}$ Although the vasculature is innervated by the parasympathetic nervous system, histologically these nerve fibres are in much greater abundance around nasal glands. ${ }^{23}$ Our results are in keeping with this as histamine had a greater effect on nasal obstruction than on hypersecretion and the opposite was true for methacholine. Borum has previously reported similar findings after nasal provocation with methacholine. ${ }^{7}$ The poor secretory response of our subjects to histamine may in part be explained by the short time intervals between serial administrations of this agonist. Secher and coworkers found that repeated administrations of histamine had a tachyphylactic effect on secretions but not on nasal airways resistance ${ }^{24}$; this effect has not been observed with methacholine. ${ }^{7}$ Differences in the pattern of response to provocation with these agonists might account in part for some of the differing results of previous studies. McLean et al failed to demonstrate nasal hyperreactivity to methacholine, but only nasal airways resistance was measured. ${ }^{5}$ The characteristics of the rhinitic subjects under study is also important, in particular whether they are allergic and whether they have perennial or seasonal symptoms. In the latter case the timing of the study in relation to the pollen season is of particular relevance. McLean et $a^{5}$ and Svensson et $^{9} l^{9}$ failed to show differences in the reactivity of subjects with seasonal rhinitis tested out of the pollen season, a time when nasal reactivity in these individuals may be normal. ${ }^{25}$ Investigators who have found nasal hyperreactivity in rhinitic subjects have, like ourselves, included patients with perennial symptoms ${ }^{6710-12}$

In this study the increase in nasal airways resistance in response to histamine was three to four times greater in subjects with than subjects without rhinitis. Borum and coworkers report differences of a similar order of magnitude between small numbers (5) of subjects with and without rhinitis. ${ }^{11}$ Several theories have been advanced to explain increased bronchial reactivity in asthmatic patients, including abnormalities of the epithelium, autonomic nervous regulation, and bronchial smooth muscle. ${ }^{2627}$ Apart from the vasculature the nose is devoid of smooth muscle in contrast to the airways. Otherwise similar explanations have been given for the increased response of the nasal mucosa seen in rhinitic subjects-increased epithelial permeability, increased sensitivity of sensory nerves, altered transmission of afferent impluses in the central nervous system, and an increased number or sensitivity of glandular or vascular receptors. $^{41114}$ Clearly in patients with allergic disease affecting both the upper and the lower airways the whole respiratory tract shows an increased responsiveness to non-specific stimuli.

We would like to thank the joint research board of St Bartholomew's Hospital for financial assistance.

\section{References}

1 Curry JJ. The action of histamine on the respiratory tract in normal and asthmatic subjects. $J$ Clin Invest 1945;25:785-91.

2 Curry JJ. Comparative effect of acetyl-beta-methacholine and histamine on the respiratory tract in normals, patients with hay fever and subjects with bronchial asthma. J Clin Invest 1947;26:430-8.

3 Itkin IH. Bronchial hypersensitivity to mecholyl and histamine in asthma subjects. $J$ Allergy 1967;40:245-56.

4 Hargreave FE, Ryan G, Thomson NC, et al. Bronchial responsiveness to histamine or methacholine in asthma: measurement and clinical significance. J Allergy Clin Immunol 1981;68:347-55.

5 McLean JA, Mathews KP, Solomon WR, Brayton PR, Ciarkowski AA. Effect of histamine and methacholine on nasal airway resistance in atopic and non atopic subjects. Comparison with bronchial challenge and skin test responses. J Allergy Clin Immunol 1977; 59:165-70.

6 Girard JP, Horvat L, Heimlich EM. Immunopathologie de la rhinite allergique tests de provocation nasaux. Rev Franç Allergol 1974;14:175-9.

7 Borum P. Nasal methacholine challenge. J Allergy Clin Immunol 1979;63:253-7.

8 Guercio J, Saketkhoo K, Birch S, Fernandez R, Tachmes L, Sackner MA.' Effect of nasal provocation with histamine, ragweed pollen and ragwed aerosol in normal and allergic rhinitis subjects [abstract]. Am Rev Respir Dis 1979;119(suppl 4):69.

9 Svensson G, Hegardt B, Lofkvist $T$. Influence of a $\beta$ adrenoceptor stimulant KWD 2131 in nasal histamine provocation tests. Acta Otolaryngol 1981;92:535-41.

10 Okuda M, Ohtsuka H, Sakaguchi K, Watase T. Nasal histamine sensitivity in allergic rhinitis. Ann Allergy 1983;51:51-5.

11 Borum P, Grønborg H, Brofeldt S, Mygind N. Nasal reactivity in rhinitis. Eur $J$ Respir Dis 1983;64(suppl 128):65-71.

12 Asakura K, Enomoto K, Ara H, Azuma E, Kataura A. Nasal responsiveness to methacholine stimulation in allergic rhinitis patients. Arch Otorhinolaryngol 1984; 
239:273-8.

13 Wihl J-A. Methods of assessing nasal reactivity. Eur $J$ Respir Dis 1984;64(suppl 128):175-9.

14 Mygind N. Mediators of nasal allergy. J Allergy Clin Immunol 1982;70:149-59.

15 Britton MG, Empey DW, John GC, McDonnell KA, Hughes DTD. Histamine challenge and anterior nasal rhinometry. Their use in the assessment of pseudoephedrine and triprolidine as nasal decongestants in subjects with hay fever. Br J Clin Pharmacol 1978; 6:51-8.

16 Nie NM, Hull GH, Jenkins JG, Steinbrenner K, Bent DH, eds. Statistical package for the social sciences. New York: McGraw Hill Book Co, 1982.

17 Borum P, Mygind N. Inhibition of the immediate allergic reaction in the nose by the beta-2 adrenostimulant fenoterol. J Allergy Clin Immunol 1980;66:25-32.

18 McLean JA, Mathews KP, Ciarkowski AA, Brayton PR, Solomon WR. The effect of topical saline and isoproterenol on nasal airway resistance. J Allergy Clin Immunol 1976;58:563-74.

19 Townley RG, Ryo UY, Kilotkin BM, Kang B. Bronchial sensitivity to methacholine in current and former asthmatic and allergic rhinitis patients and control subjects. J Allergy Clin Immunol 1975;56:429-42.
20 Bryant DH, Burns MW. The relationship between bronchial histamine reactivity and atopic status. Clin Allergy 1976;6:373-81.

21 Farmer LMD. Evaluation of the histamine intradermal test as a general indicator of allergy. $J$ Allergy 1945;16:44-7.

22 Leskowitz S, Lowell FC. A comparison of the immu- $\varrho$ nologic and physiologic responses of normal and allergic individuals. $J$ Allergy 1961;32:152-61.

23 Anggård $A$, Densert $O$. Adrenergic innervation of the nasal mucosa in cat. Acta Otolaryngol 1974;78:232-41. $\vec{\omega}$

24 Secher C, Kirkegaard J, Borum P, Maansson A, $\stackrel{\omega}{\omega}$ Osterhammel P, Mygind N. Significance of $\mathrm{H}_{1}$ and $\mathrm{H}_{2} \overrightarrow{\overrightarrow{2}}$ receptors in the human nose: rationale for topical use $x$ of combined antihistamine preparations. $J$ Allergy \pm Clin Immunol 1982;70:211-8.

25 Konno A, Togawa K, Nishihara S. Seasonal variation of sensitivity of nasal mucosa in pollinosis. $\mathrm{Arch}_{\mathrm{C}}$ Otorhinolaryngol 1981;232:253-61.

26 Boushey HA, Holtzman MJ, Sheller JR, Nadel JA. 고 Bronchial hyperreactivity. Am Rev Respir Dis 1980; 121:389-413.

27 Cross CE. Pathogenic mechanisms in asthma. In: Gershwin ME, ed. Bronchial asthma. New York: Grune and Stratton, 1981:53-71. 